\title{
CIDADE E HABITAÇÃO NA AMÉRICA LATINA (1890-1945): UMA PERSPECTIVA FOUCAULTIANA
}

\section{City And Housing In Latin America (1890-1945): A Foucaultian Approach}

\section{Joel Outtes}

Universidade Federal do Rio Grande do Sul

outtes@yahoo.co.uk

\section{Resumo}

Este trabalho trata da gênese de um discurso sobre urbanismo no Brasil e na Argentina entre 1890 e 1945 usando as ideias de Michel Foucault sobre disciplina e seu conceito de bio-poder. O padrão demográfico das maiores cidades a partir dos anos 1890 e a renovação do centro das cidades também são discutidos. Outras sessões são dedicadas aos planos propostos para as mesmas cidades nos anos $1920 \mathrm{e}$ às representações do urbano. $O$ trabalho discute ainda a oposição dos urbanistas às eleições, quando argumentavam que eram os únicos qualificados para lidarem com os problemas urbanos e deveriam ser empregados no aparelho de Estado. Eu arguo que, o urbanismo seria uma forma de criar uma cultura industrial, disciplinando a sociedade através da cidade, ainda que o proletariado industrial nunca tenha sido a maioria da população nos dois países. Mesmo se aspectos dos planos propostos para ambos os países não foram implementados, o discurso dos urbanistas pode ser visto como uma vontade de disciplinar a sociedade através da cidade, afetando a liberdade de movimento dos corpos, sendo abordado através dos conceitos Foucaultianos de biopoder e disciplina.

\section{Palavras-chave}

Foucault, urbanismo, bio-poder.

\section{Abstract}

This paper looks at the genesis of a discourse on city planning in Brazil and Argentina between 1890 and 1945 using the ideas of Michel Foucault on discipline and his concept of bio-power. The demographic pattern of the major cities in both countries from 1890 onwards and the renewals of the centres of these cities are discussed. Other sections are dedicated to the plans proposed for the same cities in the 1920s and to urban representations. The paper also discusses the planners' opposition to 
elections. They claimed that they were the only ones qualified to deal with urban problems and should be employed in the state apparatus. I argue that, if implemented, city planning was a way of creating an industrial culture, disciplining society through the city, although the industrial proletariat has never made up the majority of the population in both countries. Even if many aspects of the plans proposed for both countries were not implemented, the discourse of planners can be seen as a will to discipline society through the city. This discipline would affect the freedom of movement of human bodies, being approached through Foucault's concepts of bio-power and discipline.

\section{Keywords}

Foucault, city planning, bio-power.

\section{Introdução}

No Brasil, a gênese do urbanismo teve lugar no mesmo período no qual o governo começou a intervir em questões sociais através da criação de uma legislação trabalhista e políticas de bem estar social. De acordo com Foucault, saber, discurso e poder estão fortemente associados (Foucault, 1977, p. 4-5). O pensamento de Foucault contém aspectos que podem ser aplicados ou desenvolvidos para a história do urbanismo. De acordo com Foucault não existe verdade em nenhum discurso. 0 que há é o que ele chama de efeitos de verdade (resultados) produzidos no interior dos discursos que não são nem verdadeiros nem falsos (Foucault, 1968; Foucault, 1977). No caso do urbanismo, a criação de instituições como as comissões de planos de cidades ou comitês responsáveis por planejar e controlar o crescimento urbano no interior do aparelho de Estado pode ser vista como um destes efeitos de verdade. Houveram mudanças da virada do século XIX para o XX até os anos 1920 no movimento urbanístico Sul-americano. Em apenas alguns anos o conceito de urbanismo se expandiu de intervenções isoladas em partes específicas do território urbano para o planejamento da cidade como um todo e o controle do crescimento urbano. Em lugar de se reparar o que havia se desenvolvido de forma indesejada, apareceu a ideia de se criar regras para obrigar as coisas a acontecerem de forma prédefinida.

Foucault criticou algumas interpretações tradicionais do poder seja porque elas se centravam na questão da soberania ou em aspectos jurídicos, ou porque o poder foi analisado desde um ponto de vista Marxista em termos do aparelho de Estado. O problema de como o poder foi exercido em termos concretos, em seus detalhes, suas especificidades, suas técnicas e táticas, não foi levado em consideração em 
explicações anteriores. É a partir destas considerações que Foucault desenvolve o seu conceito de bio-poder, um conceito de poder relacionado às restrições concretas sobre aspectos do corpo humano como movimento, liberdade de ir e vir, saúde, juventude, idade, sexualidade, e por ai vai. Este conceito explica pelo menos seu interesse em temas como prisões, hospitais, asilos, e work-houses (casas de trabalho) onde tal ideia podia ser checada, observada e medida ou mesurada.

Por outro lado, o uso deste conceito apenas para a análise de relacionamentos no interior deste tipo de instituições mostra a fraqueza e limitação deste tipo de proposta. A questão que permanece da constatação desta limitação é quanto ou até que ponto este tipo de abordagem poderia ser usado para a análise do urbanismo e/ou do planejamento urbano. De fato, as decisões de urbanismo têm um impacto direto no corpo humano. A proibição de certas áreas para certas atividades, por exemplo, é uma limitação à liberdade de movimento. Uma decisão deste tipo é uma restrição de um nível infinitesimalmente pequeno sobre o corpo, sendo portanto um tipo de bio-poder. Em outras palavras, decisões de zoneamento, como o uso restrito de áreas, proibição de estacionamento em certas ruas, alocação de partes de um litoral para descarga de navios em vez de natação e banhos - tudo tem um efeito sobre a liberdade individual. Se a prisão é o lugar no qual a liberdade é completamente suprimida, uma zona urbana restritiva é um lugar onde a liberdade é pelo menos ligeiramente diminuída.

Foucault diz que se o poder fosse apenas repressivo, se ele dissesse não o tempo todo, ele não seria obedecido. Ele diz que o que mantém o poder e o faz aceitável é o fato de que ele produz coisas, induz prazeres, formata saberes e produz discursos. O poder deve ser considerado como uma rede produtiva que atravessa o inteiro corpo social em vez de uma instância negativa que tem a repressão como sua única função. De acordo com Foucault, a repressão é mais custosa, é mais cara e menos eficaz do que implementar tecnologias para induzir comportamentos. Ainda que ele não dê nenhuma estatística ou evidência quantitativa deste argumento, razão pela qual ele tem sido criticado várias vezes, espacialmente por historiadores, ${ }^{1}$ restam algumas sugestões que são apropriadas para o urbanismo. A implementação do urbanismo é uma forma aceitável de poder que produz coisas e formata saberes. $O$ conjunto de textos e técnicas de planejamento urbano é uma prova disso. Eu vou desenvolver estas ideias para o caso do urbanismo Brasileiro começando com a citação seguinte:

\footnotetext{
${ }^{1}$ Para uma crítica do trabalho de Foucault por um historiador ver Poster (1982) e Léonard (1980). Para uma discussão de Foucault com os historiadores Franceses ver Foucault (1980a). Para uma resposta 
Urbanizar é facilitar, disciplinar, embelezar, dando ao homem os elementos de uma vida que o distingue mais e mais dos estágios inferiores da comunidade humana. A urbanização da cidade dará à Prefeitura os meios para elevar o standard de vida do povo, construindo casas e protegendo a cidade dos vergonhosos mocambos (Campello, 1938. p. 3). ${ }^{2}$

Com estas palavras, José Campelo, jornalista e membro da Comissão do Plano da Cidade do Recife, celebrou a entrega de um plano para a renovação do centro desta cidade Brasileira em 1938. As ideias do seu discurso não pertencem apenas a ele. Tomemos um outro exemplo. Outro reformador social, outra data: Marcelo Mendonça, engenheiro e um dos fundadores do Instituto Central de Arquitetos no Rio de Janeiro, apresentado um trabalho em São Paulo no Primeiro Congresso de Habitação em 1931, pensava a mesma coisa:

Visitar os cortiços da Capital Federal é suficiente para se ter uma visão clara deste problema. Deles, podemos dizer, vêm todas as misérias morais e materiais e todos os vícios. Nos cortiços têm tuberculose e alcoolismo. Lá os baixos instintos se desenvolvem. Lutar contra os cortiços é tomar parte em uma batalha para elevar a moralidade e melhorar a saúde física da raça. Este meio é geralmente ocupado pela classe trabalhadora, a classe que mais especialmente precisa de mais higiene física e moral. Neste ambiente repulsivo, o trabalhador constitui sua família e estabelece seu lar. Se o seu lar é nestas condições, nada é mais desejável do que fugir para esquecer e procurar diversão no bar; ele vai mais e mais, se entregando a vícios como jogos e bebidas. De volta a sua casa, ele encontra um lar repulsivo que o faz frequentemente pensar que ele é um excluído da sociedade. A partir daí, vem a inveja e cresce o ódio contra aqueles que ele pensa responsáveis pela sua miséria. Este ambiente tem consequências desastrosas para a infância. Crianças vivem misturadas sem distinção de sexo e adotam o pior comportamento, que elas levam para a escola e o lugar de trabalho. Elas se tornam vagabundos, porque preferem a rua onde eles podem respirar e passar lá a maioria do seu tempo em lugar do seu quarto repulsivo. As garotas neste ambiente perdem todas as noções de honra e dignidade. Em resumo, os cortiços são a causa direta da falta de organização da classe trabalhadora; eles são um obstáculo absoluto ao levantamento físico e moral da classe trabalhadora. Eles devem ser demolidos (Mendonça, 1931, p. 141).

A visão dos problemas urbanos através do olhar de dois profissionais profundamente envolvidos com a gênese do urbanismo Sul-americano é surpreendente pelo preconceito e medo da massa. Este ensaio explora a genes de um discurso sobre urbanismo, localizando-o no contexto de sua paisagem cultural contemporânea. Para fazê-lo, uma visão geral e/ou um panorama do crescimento

brilhante às críticas de Léonard ver Foucault (1980b). Outras referências de relevância para este trabalho incluem Driver (1994); Eley \& Nield (1995); Noiriel (1994) e Palmer (1990).

2 Urbanizar aqui é usado no sentido de intervir na cidade para melhorar suas condições gerais. 
urbano, transformações nas cidades e a conjuntura intelectual do período serão explorados.

\section{O crescimento das cidades}

Desde o século XIX, as cidades Sul-americanas experienciaram um grande crescimento demográfico. O Rio de Janeiro dobrou sua população em 16 anos, com um crescimento de mais de um quarto de milhão de habitantes entre 1890 e 1906. Buenos Aires experimentou o mesmo processo, com sua população crescendo duas vezes, um incremento de meio milhão de habitantes (543,360). São Paulo testemunhou um processo semelhante. Sua população aumentou quatro vezes e meia em 17 anos, entre 1890-1907. Isto significou um acréscimo de quase um quarto de milhão de pessoas vivendo em seu território, trabalhando em sua economia, vivendo em suas habitações, e produzindo sua riqueza, mas também sua miséria.

Recife no Brasil e Rosário na Argentina, cidades menos importantes do que as mencionadas acima, também registraram inegáveis crescimentos demográficos. Cidades de tamanho semelhante, ambas com cerca de 100,000 habitantes na virada do século XIX para o século XX, elas experienciaram curvas populacionais comparáveis, pelo menos entre 1900 e 1920. Recife dobrou sua população neste período, quando passou dos 200,000 habitantes. Rosário dobrou seu tamanho em dez anos (1900-1910). Quando Recife atingiu 233,000 habitantes em 1920, a população de Rosário permaneceu maior, com um quarto de milhão de habitantes. Mesmo com a redução de sua taxa de crescimento de 100\% entre 1900-1910 para 25\% na década seguinte, isto significou um aumento considerável.

Se continuarmos a comparação tomando as três metrópoles - Rio de Janeiro, São Paulo e Buenos Aires - depois de 1906, a taxa de crescimento continua alta. Entre 1906 e 1920, Rio, que cresceu menos do que Buenos Aires, teve um aumento de 42.5\%. A população de Buenos Aires, ligeiramente menor do que a do Rio em 1890 ultrapassou a desta ultima cidade em 20\% em 1906, tendo um total de mais de um milhão de habitantes, e permaneceu maior do aquela do Rio desde então. Em 1920, a chamada "Paris da América do Sul" teve um crescimento populacional de mais de meio milhão comparado com o que era em 1906. Isto significou quase 700,000 habitantes adicionais vivendo em Buenos Aires, três vezes o tamanho da segunda maior cidade Argentina da época - Rosário. A partir daí, Rio sofreu um crescimento populacional de $65 \%$ entre 1920 e 1928, incorporando mais de três quartos de milhão de pessoas vivendo em seus espaços. Isto significa que em apenas oito anos ela absorveu um 
número de habitantes quase equivalente à população da segunda maior cidade Brasileira à época, São Paulo, não mais também uma cidade pequena, com uma população de mais de 800,000 pessoas. Entre 1905 e 1930, São Paulo triplicou sua população, somando mais de meio milhão de habitantes e crescendo de 279,000 para 822,400. No mesmo período, a capital Argentina, a qual cresceu menos rapidamente do que estas duas cidades Brasileiras, dobrou de população novamente, somando quase mais $1,200,000$ habitantes.

Tabela 1

População das maiores cidades do Brasil e da Argentina 1890-1928 (x 1.000 habitantes.).

\begin{tabular}{|l|c|c|c|c|c|c|c|c|}
\hline City/Year & 1890 & 1893 & 1900 & 1906 & 1910 & 1914 & 1920 & 1928 \\
\hline $\begin{array}{l}\text { Buenos Aires (2- } \\
4)\end{array}$ & 520 & $\begin{array}{c}678 \\
(4)\end{array}$ & - & 1063 & - & $1577(3-4)$ & 1738 & 2230 \\
\hline Recife (1, 5) & $\begin{array}{c}112 \\
(1)\end{array}$ & - & $\begin{array}{c}100 / 113 \\
(5)\end{array}$ & - & - & - & $233 / 239(5)$ & 346 \\
\hline $\begin{array}{l}\text { Rio de Janeiro } \\
(1,6)\end{array}$ & 523 & - & $(688)$ & 811 & - & - & 1158 & - \\
\hline Rosário (4, 7) & - & 92 & 100 & - & 200 & 223 & 250 & - \\
\hline São Paulo (1) & 65 & - & 240 & 279 & - & - & 579 & 822,4 \\
\hline
\end{tabular}

()= Interpolação. Cidades: Buenos Aires, Recife, Rio de Janeiro, Rosário \& São Paulo. Fontes:

01) Connif, Michael L.; Hendrix, Melvin \& Nohlgren, Stephen (1971): "Brazil", in Morse, Richard M.; Connif, M. \& Wibel, J. (1971): The urban development of Latin America, Stanford: Center for Latin American Studies, p. 36-52: 37; 02) Bourdé, Guy (1977): Buenos Aires: Inmigración y urbanización, Buenos Aires: Editorial Huemul S. A.; 03) Walter, Richard J. (1982): "The socio-economic growth of Buenos Aires", in Mc Gann, Thomas F. \& Stanley, S. (Eds.) (1982): Buenos Aires: 400 years, Austin: University of Texas Press, p. 67-126: 68-69; 04) Laks, Nathan (1971): "Argentina", in Morse, Richard M.; Connif, M. \& Wibel, J. (1971): The urban development of Latin America, Stanford: Center for Latin American Studies, p. 22-35: 23; 05) Baltar, Antonio B. (1951): Diretrizes de um plano regional para o Recife, Recife: Tese de Catedra, Ed. Universitaria, p. 77; 06) Agache, Donat A. (1929): Cidade do Rio de Janeiro: extensão, remodelação, embellezamento, Paris: Foyer Brésilien, p. 95; 07) Prestes Maia, Francisco (1930): Estudo de um plano de avenidas para a Cidade de São Paulo, São Paulo: Cia. Melhoramentos, p. 39.

\section{A renovação dos bairros centrais}

O enorme crescimento demográfico experienciado na América do Sul gerou uma saturação dos serviços públicos. O centro das cidades, local onde a indústria, comércio e consequentemente os empregos estavam localizados, recebeu uma parte significativa deste aumento populacional. O adensamento do centro urbano se originou principalmente do desejo da população de viver no centro, perto dos empregos (Sargent, 1974, p. 29). Esta concentração de população criou uma deterioração do estoque habitacional e das condições urbanas como um todo. Os desempregados e as frações mais despossuídas da classe trabalhadora encontraram basicamente duas formas de se alojarem. A primeira foram os cortiços ou casas de cômodos no Brasil ou conventillos na Argentina, um tipo de habitação consistindo de antigas casas da classe 
média alta com vários cômodos superpovoados. Uma outra variação possível do cortiço eram vários cômodos dispostos em torno de um pátio quadrangular construídos no mesmo lote como era o caso do clássico o cortiço de Aluízio de Azevedo. A segunda alternativa abarcava os mocambos (como eram e são chamados em Recife), vilas de malocas (como eram chamados em Porto Alegre, hoje são chamados apenas de vilas) ou favelas, barracos insalubres, efêmeros, autoconstruídos com materiais naturais como barro (taipa), palha de coqueiro ou outras palmeiras, e partes de materiais mais tradicionais como tijolos e telhas ou uma mistura de tudo isso. Estas habitações eram construídas em lotes não pertencentes aos habitantes e muitas vezes em lugares onde era difícil implantar serviços e infraestrutura urbanos como por exemplo morros e mangues. ${ }^{3}$

Quando a economia atingiu certo nível de desenvolvimento, a questão da circulação foi colocada na ordem do dia. A estrutura urbana se tornou um obstáculo ao desenvolvimento econômico. Na América do Sul, para acelerar a circulação de pessoas e mercadorias através do sistema de transportes assim como também por razões de saúde pública, haja vista os surtos de várias epidemias desde o século XIX, o Estado interveio nas cidades. Esta intervenção foi caracterizada pela renovação dos bairros centrais nas maiores cidades. No Rio houve a famosa reforma do centro, encetada durante a administração do engenheiro Pereira Passos (um Haussmann tropical de acordo com o Diplomata Barão do Rio Branco) durante sua gestão como prefeito $(1902-1906)^{4}$ (Benchimol, 1982). Esta reforma foi caracterizada pela demolição do Morro do Senado, assim como muitos edifícios, incluindo cortiços, o que foi essencial para a abertura de avenidas (Abreu, 1988, p. 63). Isso foi acompanhado por grandes trabalhos de saneamento executados sob a direção do higienista Oswaldo Cruz, que resultou em uma redução significativa da mortalidade por doenças contagiosas para certos grupos sociais, especialmente febre amarela para a população Europeia (Bodstein, 1986). ${ }^{5}$

Evidência de que circulação era fundamental durante este período é o fato de que o porto também foi reformado e aumentado, bairros da zona Sul como

\footnotetext{
3 Para uma descrição das favelas e mocambos à época ver Marianno Filho (1939).

${ }^{4}$ A reforma se baseou em um plano proposto por uma Comissão nos anos de 1870, da qual Passos era membro. Para os relatórios ver Commissão de Melhoramentos da Cidade do Rio de Janeiro; Jardim, J. R. de M. \& Silva, M. R. da, 1875 e Commissão de Melhoramentos da Cidade do Rio de Janeiro; Jardim, J. R. de M. \& Silva, M. R. da, 1876. Os dois relatórios provocaram um debate com o engenheiro Vieira Souto. Para os seus comentários ver Souto (1875) \& Souto (1876). Para um estudo do plano no contexto do período em que foi proposto ver Gantos (1993).

5 Outros trabalhos tratando da reforma durante a gestão Passos incluem Barbosa (1990); Carvalho (1984, 1988); Kessel (1983); Needell (1983, 1987, 1995); Meade (1997); Pechmann (1983); Pechmann \& Fritsch (1985) \& Pereira (1992).
} 
Copacabana e Jardim Botânico foram ligados ao centro através da construção do Túnel do Leme, inaugurado em 1906, e houve mudanças tecnológicas no sistema de transportes públicos com a substituição da tração animal por tração elétrica através da eletrificação de várias companhias de bonde como a Companhia Jardim Botânico em 1904 e as companhias São Cristovão, Carris Urbanos e Villa Isabel em 1905. Estas três empresas foram unificadas pela companhia Canadense que ganhou a concessão do suprimento de energia para a cidade, a Rio de Janeiro Tramways, Light and Power Company Limited (Abreu, 1988, p. 63, 66-67). ${ }^{6}$

São Paulo também passou por trabalhos públicos. Durante administração do Prefeito Antonio Prado (1899-1911), a Avenida Angélica foi aberta, entre outras, eo sistema de transportes também foi melhorado tecnologicamente se tornando eletrificado. Durante a administração de Raimundo Duprat (1911-1914), outras ruas foram alargadas, tais como as Libero Badaró e Boa Vista, assim como as praças da Sé e São Francisco. Naquele tempo, o viaduto Santa Efigênia foi construído junto com o alargamento da Avenida São João para permitir a construção de um anel rodoviário (Osello, 1983. p. 82). Estes melhoramentos foram parte de projetos parciais propostos no contexto de um debate sobre a organização da cidade que ocorreu entre 1906 e 1911 em São Paulo. O ponto de partida para esta discussão foi a construção do Teatro Municipal (1903-1911), um edifício eclético projetado pelo arquiteto Ramos de Azevedo e um símbolo da modernidade Europeia implementada pela elite governamental. A construção do teatro ao lado do Vale do Anhangabaú, onde um Riachuelo infectado recebia os esgotos de um matadouro, mas de feições ainda rurais como plantações de verduras e chá, originou uma série de propostas para o embelezamento do vale e sua paisagem (Simões, 1990, p. 79-80). A primeira destas propostas foi apresentada à Câmara Municipal pelo ex-Diretor de Obras Públicas do Rio, Augusto Carlos da Silva Telles, quem se tornou vereador em São Paulo. A proposta era caracterizada por preocupações estéticas, e a vontade de resolver problemas de circulação relacionadas à estreiteza da Rua Libero Badaró, e foi submetida para análise pela Comissão de Obras, Justiça e Finanças da Câmara Municipal (Simões, 1990, p. 80-83).

A proposta foi esquecida por um ano e meio apesar do apoio de outros vereadores, quando foi re-adotada por Silva Telles em 1908, apresentada como lei e estudada pelos engenheiros Victor da Silva Freire (Português radicado no Brasil) e Eugênio Guillem, Diretor e Vice-Diretor da Direcção de Obras Municipaes

\footnotetext{
${ }^{6}$ Para um estudo sobre esta companhia ver McDowall (1988).

URBANA, V.6, no 8, jun.2014 - Dossiê: Cidade e Habitação na América Latina - CIEC/UNICAMP
} 
respectivamente (Simões, 1990, p. 84-86). O projeto recebeu emendas nas comissões da Câmara e se transformou em lei na qual as ideias de Telles foram simplificadas por razões financeiras por causa de desapropriações e interesses privados, perdendo seu ideário estético e se tornando meramente uma resposta aos problemas de tráfego. ${ }^{7}$ Com a aprovação da lei, a Câmara negociou com o governo estadual o apoio aos melhoramentos e sua inclusão no orçamento de 1911 (Simões, 1990 , p. 92). Ao mesmo tempo, o governo provincial promoveu outro projeto para a cidade projetado pelo arquiteto Samuel Augusto das Neves da Secretaria de Agricultura, Commercio e Obras Publicas, o qual foi publicado no jornal Correio Paulistano. Este projeto respondeu aos interesses dos proprietários de terras na região e foi provavelmente projetado de acordo com eles, permitindo a reconstrução de seus edifícios na Rua Libero Badaró em troca da doação de terras para sua extensão e alinhamento com outras ruas (Simões, 1990, p. 98-99).

O projeto de Neves propôs um boulevard haussmaniano no Vale do Anhangabaú, em oposição às ideias avançadas por Victor da Silva Freire e Eugênio Guillem, as quais eram próximas das ideias do urbanista Austríaco Camilo Sitte (18431903) em seu livro Der Städtebau nach seinen künstlerischen grundsätzen (A construção de cidades segundo seus princípios artísticos), que valorizavam a conservação do desenho espontâneo existente de bulevares estreitos. Mais do que uma confrontação entre as administrações municipal e estadual, as duas propostas levaram a um debate que teve o seu momento mais importante na palestra proferida pelo engenheiro Victor da Silva Freire na Escola Polytechnica a convite de sua associação de estudantes. Publicada na Revista Polytechnica, o periódico técnico e científico da associação de estudantes, a palestra é considerada um dos textos fundadores do urbanismo Brasileiro, ao menos em São Paulo (Freire, 1911).

Notável por suas referências a desenvolvimentos em urbanismo a nível internacional-incluindo ensino - esta palestra mencionava urbanistas estrangeiros como Charles Bull, Baumeister, Hénard, Charles Mulford Robinson, e por último mas não menos Camilo Sitte, sua principal fonte de inspiração. Nesta ocasião, Victor da Silva Freire se baseou na experiência estrangeira para levantar uma questão importante: em lugar da adoção de projetos parciais como aqueles que estavam sendo discutidos, um plano geral deveria ser elaborado para a cidade (Freire, 1911, p. 101 \& 110). Alguns meses depois da palestra de Victor Freire, o prefeito contratou o paisagista Francês Joseph Antoine André Bouvard para analisar os projetos

\footnotetext{
7 Lei no. 1,3331 de 06 de junho de 1910, cf. Simões (1990): 88-93.

URBANA, V.6, no 8, jun.2014 - Dossiê: Cidade e Habitação na América Latina - CIEC/UNICAMP
} 
concorrentes. Em seu relatório, Bouvard propos uma solução conciliatória, adotando ideias de ambas as propostas e dividindo a execução do seu projeto entre os autores dos esquemas precedentes. O projeto urbano deveria ser realizado por engenheiros municipais, enquanto que os edifícios seriam projetados pelo escritório de arquitetura de Samuel das Neves. As propostas foram finalmente executadas no centro da cidade de São Paulo durante o período de Raimundo Duprat na Prefeitura (Osello, 1983, p. 60-63 \& Simões, 1990, p. 116-126).

Recife também passou por um processo semelhante. Um dos bairros centrais da cidade foi renovado, com a melhoria das condições de tráfego através da reforma de seu porto entre 1909 e 1913. Este projeto foi também realizado por razões de saúde pública. Na realidade, um projeto de esgoto e abastecimento d'água foi proposto pelo engenheiro sanitarista Francisco Saturnino de Brito e executado entre 1909 e $1917 .^{8}$ Este período foi ainda de mudanças significativas na circulação urbana. Os bondes de companhias como a Recife Street Car Company, que eram originalmente puxados por tração animal foram eletrificados em 1914, um pouco mais tarde do que as maiores cidades Brasileiras, quando a concessão do serviço foi ganha pela Pernambuco Tramways, Light and Power Limited, companhia de propriedade de acionistas Ingleses, os quais tinham adquirido a concessão de eletricidade para a cidade. $^{9}$

Do outro lado do Rio Paraná, na Argentina, desenvolvimentos semelhantes tiveram lugar na cidade capital. Mais cedo do que nas cidades Brasileiras, e depois da aprovação de um projeto pela Câmara Municipal em 1889 durante a administração do Prefeito Torcuato de Alvear (1880-1887), a abertura da Avenida de Mayo foi implementada (Bragos, 1991, p. 8; Hardoy, 1955, p. 105), ligando a Plaza de Mayo, onde a Casa Rosada, o palácio presidencial, está localizado, à Plaza Lorea, onde o edifício do Parlamento Nacional foi construído e inaugurado em 1906 (anteriormente estava localizado na Plaza de Mayo) (Scobie, 1974, p. 109-113). A Avenida de Mayo foi inaugurada em 1894 e terminada em 1896 (Hardoy, 1955, p. 100). Buenos Aires também teve um projeto proposto por Bouvard. Em 1906, antes de sua viagem a São Paulo, Bouvard estava ocupado com esta tarefa quando uma comissão foi nomeada

\footnotetext{
8 Para a renovação do porto e do bairro ver Lubambo (1988). Para o projeto de saneamento ver Brito (1917).

9 Para a história do bonde a tração animal e sua influência no desenvolvimento da cidade e vice-versa ver Zaidan (1991). Para o bonde elétrico ver Mota (1985).
} 
para trabalhar com ele. ${ }^{10} \mathrm{O}$ paisagista Francês elaborou ainda um plano para a cidade de Rosário (San Vicente, 1986).

Da mesma forma que em São Paulo alguns anos depois, o projeto de Bouvard para Buenos Aires conciliou estudos anteriores propostos por profissionais locais. No começo do século XX, um debate teve lugar, relacionado à celebração do centenário da independência da Argentina, com relação à transformação física da capital. De um lado estavam os defensores das avenidas perpendiculares seguindo o desenho da grelha, característica da colonização hispânica, que já existia na cidade. De outro lado estavam os partidários de avenidas diagonais como uma solução para os problemas de circulação. Este debate aconteceu no Parlamento Nacional em 1905. O projeto das avenidas perpendiculares foi defendido pelos deputados Eugenio Badaró e Canton, enquanto que o projeto das ruas ortogonais foi apoiado por três deputados - Miguel Desplats (autor de um trabalho sobre melhoramentos urbanos em 1906) (Desplat, 1906), Varela e Perez. (Novick, 1990, p. 4).

Outras propostas foram apresentadas durante este debate. Um terceiro projeto foi elaborado pelo arquiteto Henrique Chanourdie, diretor de Arquitectura, a revista da Sociedad Central de Arquitectos (Chanourdie, 1906-1907). Este era o contexto das ideias urbanísticas quando Carlos Torcuato de Alvear, prefeito de Buenos Aires (1907-1909), convidou Bouvard para elaborar um projeto para a cidade. O debate parlamentar acabou em 1912, com a promulgação de leis de expropriação para abrir duas avenidas diagonais partindo da Plaza de Mayo assim como uma larga avenida Norte-Sul. Um ano antes, um código de obras foi aprovado com o controle da regularidade das fachadas sendo o seu aspecto principal objetivo. ${ }^{11}$ Apesar de sua diversidade e riqueza, todos estes projetos propostos em ambos países foram caracterizados por uma abordagem parcial e fragmentada do urbanismo, sem levar em consideração o território inteiro da cidade como unidade de intervenção.

\section{A gênese do urbanismo}

Durante as duas primeiras décadas do século XX a ideia do urbanismo, definida como um projeto tomando a cidade inteira como sítio de intervenção, foi estabelecida tanto no Brasil como na Argentina. Na Argentina, em 1906, o arquiteto Christophersen apontou a necessidade da elaboração de um plano para Buenos Aires, e no Brasil o

\footnotetext{
10 Esta comissão era composta pelo paisagista Francês Carlos Thays, Diretor do Servicio de Parques y Paseos de Buenos Aires; do engenheiro Carlos Maria Morales; do vereador Fernando Perez, membro da Commisión de Avenidas e do Diretor da Commisión Nacional de Obras Públicas, Higiene y Seguridad Social, o engenheiro Anastásio Iturbe, cf. Novick (1990): 5.

${ }^{11}$ As leis para a abertura das avenidas tinham os números 8.854 e 8.855 , cf. Novick, A. (1990): 4-5.
} 
engenheiro Victor da Silva Freire, quando convidado por estudantes da Escola Polytechnica para fazer uma palestra em 1911 sobre dois planos concorrentes para o centro de São Paulo, falou da mesma necessidade. Em 1917, Saturnino de Brito, um engenheiro sanitarista engajado no planejamento e construção de um sistema de esgoto e abastecimento d'água para Recife, ecoou a mesma ideia.

Em ambos os países, os anos 1920s assinalaram o nascimento dos primeiros planos modernos propostos para suas cidades. Em 1923, uma comissão foi criada em Buenos Aires, a Comisión de Estetica Edilicia, encarregada de propor um plano para a cidade e no Rio de Janeiro, Alfred Agache, um urbanista Francês, foi nomeado com o mesmo propósito quatro anos mais tarde (Agache, 1930). A Assembleia Legislativa de Pernambuco votou no mesmo ano uma lei autorizando o governador a empregar Agache para elaborar um plano para a capital, Recife. (Outtes, 1997, p. 67-70). Em 1929 o engenheiro Prestes Maia estava também trabalhando no chamado Plano de Avenidas para São Paulo (Maia, 1930). ${ }^{12}$ Estas cidades, apesar das diferenças de população, tiveram a mesma preocupação no mesmo período: planejar seu crescimento e controlar sua expansão. Esta nova atitude foi um ponto de inflexão no paradigma de pensar e intervir nas cidades. Não se tratava mais meramente de abrir novas avenidas para melhorar a circulação do tráfego or renovar os centros urbanos infestados de cortiços como anteriormente.

Nos 23 anos separando as ideias de Christophersen e a publicação dos planos de Agache e Prestes Maia, nasceu o urbanismo no Brasil e na Argentina, mudando a prática nesta área em apenas alguns anos. Novos procedimentos foram criados nesta prática. Recolher informações detalhadas das condições urbanas antes do planejamento se tornou uma nova preocupação, do qual se originaram inquéritos sobre crescimento demográfico, saúde pública e epidemias passadas, sistemas de transporte, o orçamento municipal e a estória de vida das cidades. Novas instituições foram criadas para monitorar e garantir a implementação dos planos. Depois de serem aprovados, os planos sempre resultaram em leis estabelecendo novos códigos de obras mais complexos e restritivos.

A implementação dos planos e a institucionalização do urbanismo como uma disciplina autônoma aconteceu em ambos os países sob regimes políticos intervencionistas e antiliberais, como os anos Vargas no Brasil (1930-1945), especialmente a ditadura do Estado Novo (1937-1945); e na Argentina durante os

\footnotetext{
12 Maia discutiu a implementação dos seus planos durante sua gestão como prefeito (1938-1945) em Maia (1941, 1945). A crescente literatura sobre Maia inclui Anonymous (1996), Campos (1996), Nunes (1996), Pontes (1996), Toledo (1996) \& Zmitrowicz (1996).
} 
governos militares do General José F. Uiriburu (1930-1932) e dos presidentes Augustín P. Justo (1932-1938), Roberto M. Ortiz (1938-1940) e Ramon S. Castillo (1940-1942) (Scobie, 1971, p. 260-261). Sob estes governos algumas das propostas de Agache para o Rio de Janeiro foram implementadas, o Plano de Avenidas em São Paulo foi executado, assim como parte das propostas contidas no plano de Nestor de Figueiredo para Recife. Em Buenos Aires a Oficina del Plan de Urbanización (Escritório do Plano de Urbanização) foi criada em 1932, seguida por um plano proposto em 1935 pelo urbanista Alemão Werner Hegemann e os Argentinos Kalnay e Carlos Maria della Paolera.

Por um lado, houve uma nova prática relacionada com a gestão urbana. Por outro lado, houve o nascimento de um novo tipo de saber: o urbanismo ou o que foi chamado de "a ciência do planejamento de cidades". Esta chamada "nova ciência" implicava na criação de novos produtores deste novo saber, novos intelectuais e profissionais, os urbanistas. Este saber foi institucionalizado através do ensino do urbanismo nas universidades. Em 1929, a primeira cátedra em urbanismo foi criada na Argentina na Faculdad de Ciencias Fisicas y Naturales da Universidad de Rosario, quando della Paolera foi nomeado para a posição. No Brasil, disciplinas de urbanismo foram instituídas em São Paulo em 1923 no Mackenzie College e em 1926 na Escola Polytechnica (Ficher, 1989: 1, p. 230), no Rio de Janeiro na Universidade do Distrito Federal em 1935 e em Recife na Escola de Belas Artes no ano seguinte.

Os planos propostos para a cidade inteira, assinalando uma nova escala espacial para resolver os problemas urbanos, foi seguida por uma nova racionalidade. Esta racionalidade incluiu aspectos como Taylorismo (administração científica), a racionalidade técnica e a recriação da cidade como espelho da fábrica, refletindo sua lógica funcional, mesmo se estes países tinham economias agrícolas e não industriais à época, com a maioria da população vivendo em áreas rurais, apesar da concentração da população Argentina em Buenos Aires. Entre os anos 1920 e 1940 houve mudanças nas representações sobre a cidade. Seguindo o discurso dos urbanistas, a racionalidade técnica e a lógica científica deveriam regular as atitudes e comportamentos da sociedade através da cidade. A Engenharia, profissão técnica por excelência, assumiu postos importantes na administração municipal. Um número significativo de prefeitos nas cidades Brasileiras mais importantes tinha diploma de engenharia entre os anos de 1930-1945. A hegemonia da tecno-ciência resultou na ideia de que o urbanismo era científico e de acordo com os urbanistas era considerado de interesse geral de toda a sociedade. O discurso dos engenheiros e urbanistas 
incluiu a ideia de que as instituições representativas, típicas das sociedades democráticas, eram ineficientes. Na visão deles, a política estava em oposição às necessidades da cidade moderna. Este autoritarismo de tornou realidade, ao menos no nível municipal, sob os governos intervencionistas e antiliberais dos anos 1930 e 1940 .

O movimento pela reforma urbana e da habitação era parte de um movimento maior: o movimento pela reforma social. Neste sentido, urbanistas, médicos, engenheiros, advogados, prefeitos e ativistas do movimento pela habitação devem ser vistos como reformadores sociais. Antes da institucionalização do urbanismo e da adoção das políticas habitacionais pelo Estado, estes reformadores sociais e da adoção de políticas habitacionais pelo Estado, estes reformadores sociais frequentavam organizações como associações profissionais, entidades filantrópicas, sociedades beneficentes, ligas antialcoolismo, clubes de engenheiros, institutos de engenheiros e federações médicas. Foi nestes espaços, que o ideal reformador apareceu, foi debatido e se desenvolveu. A linguagem e o discurso do novo saber foram forjados nestas instituições, onde as competências profissionais foram também legitimadas.

O discurso dos urbanistas neste período incluiu um projeto de disciplinar a sociedade através da cidade. Este projeto foi investido com as ideias correntes na paisagem cultural do período, como positivismo, higiene social e eugenismo. Como o objetivo era modificar o comportamento diário e as atitudes da população através da indução de certas regras e padrões, ele deve ser visto como uma prática disciplinar semelhante em alguns aspectos ao aprisionamento tal como analisado por Foucault (1975a).

\section{Representações urbanas}

O discurso dos urbanistas produziu um retrato da cidade, da sociedade e do poder político. Uma linha coerente de pensamento foi construída na cabeça dos profissionais, que inventaram uma questão que nasceu nas cidades e construiu uma representação do cotidiano chamada "problemas urbanos". Como toda linha, esta é um conjunto de pontos estreitamente ligados para ser visível. O ponto de partida era a habitação. Na visão dos urbanistas, a moradia na qual os pobres ou mesmo a classe trabalhadora Morava era suja e perigosa. Se a casa era vista como insalubre, indesejável, inservível, como estes que olhavam para a habitação desta forma olhariam o conjunto, a cidade? Será que aqueles que viam a casa como insalubre viam a cidade como saudável, limpa, bonita? O retrato da cidade que eles nos revelaram é dúbio: um em cores, o outro preto e branco, ambos revelados no mesmo velho, 
estressado e sujo papel fotográfico. De um lado, a exuberância da natureza - sua luz e as tonalidades do arco-íris - aparecem nas fotos em cores:

As cidades Brasileiras, com suas alegres avenidas, suas expressivas montanhas, suas praias sedutoras, seu céu limpo e azul, tem algo magnético, fascinante e absorvente que embebeda e encanta quando se as vê pela primeira vez (Oliveira, 1940a, p. 187).

Esta não é a fotografia inteira da cidade. A luz é apagada, as cores se extinguem, e mesmo o magnetismo, a fascinação, a maravilha e o prazer da embriaguez são transformados em repulsão, distância e depressão quando o mesmo fotógrafo vira a face do mesmo papel para mostrar uma imagem preto e branco:

Infelizmente, há também, nas cidades de nossos países, o outro lado da moeda, o oposto da beleza, a sombra da beleza magnífica da pintura. Nas cidades Brasileiras, há também, como nas cidades de outros países, conjuntos de cortiços, áreas deterioradas e todos os tipos de moradas miseráveis (Oliveira, 1940a, p. 187).

De várias imagens como esta, um panorama é construído, estabelecendo uma ligação, uma coerência e uma sequência entre cada slide. Esta ligação é o efeito determinante do ambiente no homem, mulher, família e sociedade. Pensava-se que o ambiente podia influenciar o homem e determinar seu comportamento, mas este mesmo ambiente podia ser transformado pelo homem, transformando as precondições desta influência. Tal reflexão é encontrada na mente dos urbanistas Sul-americanos:

O objetivo principal do urbanismo é a habitação salubre, lugares de trabalho higiênicos, casas de entretenimento aeradas e gosto estético para a alegria do homem. O poder público deve prover amplos espaços abertos, para a prática de esportes, jardinagem e laser para o pobre, porque tem se provado através de estatísticas que onde há parques, piscinas, praças, playgrounds, saúde e higiene são melhorados de forma que a moral é mudada e a delinquência infantil diminui de forma notável (Prado, 1941, p. 42). ${ }^{13}$

\section{Os urbanistas no poder.}

Em paralelo a este processo, outro movimento teve lugar, o da crítica à administração urbana e através dela ao governo. Um engenheiro no Primero Congreso Argentino de Urbanismo em 1935 observou:

Frequentemente, nos encontramos nas municipalidades com pessoas que tem um critério muito pessoal com relação a todos os problemas inerentes à cidade. Influenciados por fatores políticos, eles autorizam concessões ou implementam certas obras, algumas vezes inoportunas ou precipitadas, sem

\footnotetext{
${ }^{13}$ Para outros depoimentos de conteúdo semelhante ver Estelita (1935) \& Mello (1929): 150 \& 153. 
levar em conta as prioridades... obrigando o mesmo vilarejo a pagar uma soma exorbitante em detrimento de sua economia por causa de uma direção sem sentido... (Suffriti, 1935, p. 131).

Uma das justificativas mais comumente empregadas para criticar o governo municipal era a alternância das pessoas no poder. A mudança de um prefeito em uma municipalidade significava interrupção em obras públicas e seu abandono. A implementação de ideias de longo prazo tais como aquelas características dos planos urbanísticos nunca poderia ser realizada desta forma. As instituições representativas, típicas de sociedades democráticas, eram consideradas ineficientes aos olhos dos urbanistas. No Brasil, em 1940, um cronista da revista Urbanismo e Viação apontou que:

A coisa mais importante, de toda forma, não é desenhar o plano mas chegar na fase de execução... A pior coisa é quando administradores mudam e ninguém quer seguir as regras adotadas por seus predecessores. Vamos desenhar um plano, se necessário, mas vamos declarar também a conveniência de uma nova mentalidade, que pode ver os benefícios de uma mentalidade única. O ideal, em uma medida deste tipo, é não perder esforços em atividades esparsas mas definir as regras gerais e segui-las inflexivelmente, por décadas e décadas (Anônimo, 1940, p. 237).

A crítica da ineficiência se torna portanto uma recusa da democracia. Na mente dos urbanistas, um modelo de governo é construído. Este governo deveria ser forte, autoritário e centralizado com apenas profissionais nos postos principais. Eleições, a forma pela qual aqueles que às vezes representam os interesses da população mas não são especialistas podem ascender ao poder, não são vistas como um elemento positivo da polítca. Alguém que estivesse sentado na sala do Grêmio Polytechnico em São Paulo em 1911, teria ouvido a este tipo de ideias proferidas por um palestrante convidado, quem aproveitaria sua erudição sobre a experiência internacional para alimentar seu argumento:

A administração municipal, na Grã Bretanha, é ocupada por homens de negócios: os vereadores são recrutados quase que exclusivamente entre os comerciantes, industriais e chefes de companhias. Ser eleito vereador é considerado uma verdadeira distinção, concedida pelas classes que representam o papel da aglomeração nas forças econômicas da nação. Esta escolha é tradicionalmente independente de qualquer diferença em crenças políticas. O processo eleitoral é muito fácil... A lei estipula que quando há apenas um candidato ele deve ser considerado eleito diretamente, a percentagem das eleições que vai para as urnas é baixa, mesmo em tempos quando há mais efervescência na luta partidária. Desta forma, os nomes designados têm a confiança dos cidadãos... É muito comum encontrar um prefeito que continua vinte ou trinta anos ininterruptos no posto... Este fator de competência é o que possibilita que as municipalidades Inglesas e Alemãs 
resolvam as questões mais complicadas de forma rápida e eficiente. Em cada posto está o homen certo. As polêmicas sobre o serviço oferecido são raras: aquele que está no governo é o que mais sabe... Durante este tempo a Câmara Municipal Parisiense se tornou impotente com longos debates. Isto é porque, apesar da natureza precisa e da inteligência da raça, é muito fácil para um incompetente alcançar o posto de vereador (Freire, 1911, p. 95-96).

Não é difícil imaginar que tipo de regime político seria apreciado de acordo com este pensamento. Em um governo em que há complete continuidade não há espaço para a democracia ou necessidade de eleições. O regime político correspondente a esta imagem é a ditadura. De fato, a história mostrou que foi exatamente este tipo de governo que ascendeu ao poder no Brasil com o golpe de Estado de 1937, convidando urbanistas para se tornarem prefeitos, e, ao fazê-lo, ganhando o seu apoio. José Estelita, Diretor da Secretaria de Viação e Obras Públicas do Estado de Pernambuco, viu este processo da seguinte forma:

No passado, antes do golpe de estado de Novembro de 1937, a politicagem dominava as cidades, onde a política cresceu e se desenvolveu não podia existir nem disciplina nem respeito pela lei. A falta de disciplina urbana era um reflexo da falta geral de disciplina do país. Antes do Estado Novo, falar de urbanismo, a ciência que pode ser definida como coordenação disciplinar, a ciência que é o relacionamento perfeito entre as coisas, teria sido utópico. Hoje, de todo jeito, a ambiência é diferente e já podemos trocar ideias em congressos e adotar com vantagem medidas para sanear as cidades (Estelita, 1941, p. 44).

\section{Conclusão}

Assim como no caso das prisões, discutido por Foucault, o nascimento do urbanismo esteve ligado a um projeto de transformação dos indivíduos. A forma que os criminosos eram discutidos no discurso da criminologia, ou mesmo nas páginas relacionadas dos jornais, parece muito com a forma como os habitantes pobres urbanos da favela, do cortiço ou do mocambo eram descritos pelos urbanistas. Foucault explica tal descrição dos criminosos como uma forma de constituir o povo enquanto um corpo moral separado da delinquência. Em uma sociedade industrial na qual se requer que parte da riqueza não esteja nas mãos de quem a possui, mas nas de quem as faz trabalhar (como no caso das máquinas nas fábricas), assim permitindo a extração do lucro, a constituição do povo como um corpo moral é vista como uma forma de proteger esta riqueza (Foucault, 1975b, p. 132-133). De forma semelhante, a descrição do pobre urbano como degenerado é uma forma de proteger a riqueza investida na cidade, a qual está muitas vezes localizada em espaços desprotegidos e poderia ser facilmente danificada. É também uma forma de justificar a intervenção em 
; areas deterioradas para renová-las através da construção de um novo ambiente construído de acordo com as necessidades de acumulação de capital.

Respostas para estas questões foram encontradas através de uma genealogia do urbanismo, a qual foi feita através de "uma forma de história que dá conta da constituição de saberes, discursos, e domínios de objetos" (Foucault, 1971, p. 15-38). Foucault, escrevendo sobre as prisões, menciona que os delinquentes são representados como perigosos e imorais, fazendo com que a classe trabalhadora sinta medo e se afaste deles. Ele aponta o papel das páginas criminais nos jornais como um instrumento para a construção desta imagem. Se compararmos isto com a representação dos urbanistas, vemos que aqueles que moram em favelas, malocas, mocambos e cortiços em cidades não planejadas são descritos de forma similar. A propaganda foi parte do movimento pela institucionalização do urbanismo enquanto um novo campo do saber. A presença de jornalistas em comissões dos planos de cidades, como foi o caso em Recife, assim como a primeira página de certos jornais diários apresentando o estado da discussão urbanística, parece ser uma boa evidência disso. Entrevistas com urbanistas foram publicadas em jornais e muitos deles fizeram palestras transmitidas pelo rádio divulgando princípios de urbanismo. Considero importante e fascinante estudar o discurso dos urbanistas. Para mim, eles revelam parcialmente como a sociedade e a cidade foram pensadas para serem formatadas de acordo com os princípios de uma lógica industrial, ou, ao menos como algumas tentativas foram feitas para conformá-la nesta direção, como foi o caso com o urbanismo.

\section{Referências.}

ABREU, M. A. Evolução Urbana do Rio de Janeiro. Rio de Janeiro: IPLANRIO-Jorge Zahar Editor, 1988, 2a ed.

AGACHE, D. A. H. Cidade do Rio de Janeiro: extensão, remodelação, embellezamento. Paris: Foyer Brésilien, 1930.

ANÔNIMO. O plano da cidade. Urbanismo e Viação, Rio de Janeiro, v. 3, n. 8, p. 237, Abril de 1940.

ANÔNIMO. Um pintor chamado Prestes Maia. Cidade, São Paulo, v. 3, n. 4, p. 60-75, 1996.

BENCHIMOL, J. L. Pereira Passos: um Haussmann Tropical, as transformações urbanas do Rio de Janeiro no inicio do século XX. Rio de Janeiro: Dissertação de Mestrado, COPPE-UFRJ, 1982. 
BODSTEIN, R. C. A. Práticas sanitárias e classes populares do Rio de Janeiro. Revista Rio de Janeiro, Rio de Janeiro, v. 1, p. 4, p. 33-43, 1986.

BRAGOS, O. El urbanismo Francés en América Latina: D. A. Agache en Río de Janeiro, J. C. N. Forestier en Buenos Aires. Cuadernos del CURDIUR, n. 54, 1991.

BRITO, F. R. S. Saneamento do Recife. Recife: Typographia da Imprensa Official, 1917,2 vols.

CAFFERATA, J. In: ANÔNIMO. 10 Congresso Pan-Americano da Vivenda Popular. Urbanismo e Viação, v. 2, n. 6, p. 161-165, Dezembro de 1939.

CAMPELLO, J. Entregue à municipalidade o plano definitivo de reforma do bairro de Santo Antônio. As solenidades de hontem no Theatro Santa Isabel. Os discursos do Interventor Federal, Prefeito da Capital e Jornalista José Campello. Folha da Manhã, Recife, 24 de Abril de 1938, p. 1, 3, 5, 7 \& 8, p. 3.

CAMPOS, E. São Paulo na visão classi[ci]sta de Prestes Maia. Cidade, São Paulo, v. 3, n. 4, p. 42-45, 1996.

CARVALHO, R. C. M. Urban Planning in Rio de Janeiro: A Study of the Urban Redevelopment Plan During the Passos Administration (1902-1906). Ithaca, NY: Master's thesis, Cornell University, 1984.

CARVALHO, R. C. M. The Search for a Modern City: The Urban Renewal Plan for Rio de Janeiro, 1902-1906. Colloqui: A Journal of Planning and Urban Issues, Ithaca, NY, pp. 8-17 Primavera de 1988.

CAVALCANTI, J. O Plano de remodelação de Belém. Urbanismo e Viação, Rio de Janeiro, v. 6, n. 26, p. 33-34, Abril-Maio de 1943.

CHANOURDIE, E. La transformación edilícia de Buenos Aires. Arquitectura, Buenos Aires, v. 3, n. 39, p. 95-103, 1906-1907.

COMMISSÃO DE MELHORAMENTOS DA CIDADE DO RIO DE JANEIRO; JARDIM, J. R. M \& SILVA, M. R. Primeiro relatório da Commissão de Melhoramentos da Cidade do Rio de Janeiro. Rio de Janeiro: Imprensa Nacional, 1875.

COMMISSÃO DE MELHORAMENTOS DA CIDADE DO RIO DE JANEIRO; JARDIM, J. R. M \& SILVA, M. R. Segundo relatório da Commissão de Melhoramentos da Cidade do Rio de Janeiro. Rio de Janeiro: Imprensa Nacional, 1876.

DESPLAT, M. Mejoras urbanas. Buenos Aires: Talleres Gráficos de la Penitenciaria Nacional, 1906.

DÓRIA, H. Sugestões para a solução dos problemas das casas operárias. In: INSTITUTO DE ENGENHARIA DE SAO PAULO. Annaes do $\mathbf{1}^{0}$ Congresso de 
Habitação. São Paulo: Escolas Profissionaes do Lyceu Coração de Jesus, p. 51-54, 1931.

DRIVER, F. Bodies in Space: Foucault's Account of Disciplinary Power. In: JONES, C. \& PORTER, R. (Eds.) Re-Assessing Foucault, reimpresso em DEREK, G. \& BARNES, T. (Eds.) Reading Human Geography: The Poetics and Politics of Enquiry. London: Arnold, 1997 (1994), p. 279-289.

ELEY, G. \& NIELD, K. Starting Over: The Present, the Post-Modern and the Moment of Social History. Social History, v. 20, n. 3, p. 355-365, 1995.

ESCOBAR, A. Culture Sits in Places: Reflections on Globalism and Subaltern Strategies of Localization. Political Geography, v. 20, n. 2, p. 139-174, 2001.

ESTELITA, J. Os parques Norte-Americanos e o problema da criminalidade, Revista da Directoria de Engenharia, Rio de Janeiro, v. 2, n. 17, p. 424-426, 1935.

ESTELITA, J. Fala á 'Urbanismo e Viação' o Representante de Pernambuco. Urbanismo e Viação, v. 4, n. 13, p. 44, Março de 1941.

FICHER, S. Ensino e profissão: o curso de engenheiro-arquiteto da Escola Politécnica de São Paulo. São Paulo: Tese de Doutorado, Departamento de História, Universidade de São Paulo, 1989, 2 vols., FOUCAULT, M. Politics and the study of discourse. In: GORDON, C.; MILLER, P. \& BURCHELL, G. The Foucault Effect: Studies in Governmentality, with Two Lectures by and an Interview with Michel Foucault. Wheatsheaf: Havester, 1991 (1968), pp. 53-72.

FOUCAULT, M. Nietzche, la génealogie, I'histoire. In: Hommage à Jean Hyppolite. Paris: Presse Universitaire de France, 1971, traduzido por CATAN, M. como Nietzche, a genealogia e a história. In: FOUCAULT, M. Microfísica do poder. Rio de Janeiro: Graal, 1979, 9a ed., 1990, p. 15-38.

FOUCAULT, M. O nascimento da medicina social. In: FOUCAULT, M. Microfísica do Poder. Rio de Janeiro: Graal, 1979, 9a ed., p. 79-98.

FOUCAULT, M. Surveiller et Punir: naissance de la prison. Paris: Gallimard, $1975 a$.

FOUCAULT, M. Entretiens sur la prision: le livre et sa méthode. Magazine Littéraire, n. 101, 1975b, traduzido por DAMIÃO, M. M. como Sobre a prisão. In: FOUCAULT, M. Microfísica do Poder. Rio de Janeiro: Graal, 1979, ga ed., p. 129-144.

FOUCAULT, M. Verité et pouvoir. L'Arc, Paris, n. 70, p. 1-14, 1977, traduzido por HOLZMEISTER \& SOUZA como Verdade e poder, In: FOUCAULT, M. Microfísica do poder, Rio de Janeiro: Graal, 1977, 9a ed., p. 4-5. 
FOUCAULT, M. La poussière et le nuage. In: PERROT, M. (Ed.) L'impossible prison: recherches sur le système pénitentiaire au XIXe siècle. Paris: Editions du seuil, 1980a, p. 29-39

FOUCAULT, Table ronde du 20 mai 1978. In: PERROT, M. (Ed.) L'impossible prison: recherches sur le système pénitentiaire au XIXe siècle. Paris: Editions du seuil, 1980b, p. $40-58$

FREIRE, V. S. Melhoramentos de São Paulo. Revista Polytechnica, São Paulo, n. 33, p. $91-145,1911$.

GANTOS, M. C. Progresso e crise urbana: a Comissão de Melhoramentos da Cidade do Rio de Janeiro (1870-1876). Niterói: Dissertação de Mestrado, Departamento de História, UFF, 1993.

GODOY, A. A. Algumas idéias sobre a remodelação das cidades. In: SOCIEDADE BRASILEIRA DE HYGIENE Annaes do Primeiro Congresso Brasileiro de Hygiene. Rio de Janeiro, p. 39-47, 1923.

HARDOY, J. E. Theory and Practice of Urban Planning in Europe (1850-1930): Its Transfer to Latin America. In: HARDOY, J. E. \& MORSE, R. (Eds.) Rethinking the Latin American City. London \& Baltimore: JHUP, p. 20-49, 1992.

HARDOY, J. F. et allí. Evolución de Buenos Aires en el tiempo y en el espacio. Revista de Arquitectura, Buenos Aires, v. 40, n. 375, p. 25-84 \& n. 376-377, p. 25-125, 1955.

KESSEL, M. I. Crescimento urbano e reforma urbana em metrópole não industrial: o caso do Rio de Janeiro no período 1870-1920. São Paulo: Dissertação de Mestrado, DCS-PUC, 1983.

LÉONARD, J. L'historien et le philosophe: à propos de Surveiller et Punir; naissance de la prison. In: PERROT, M. (Ed.) L'impossible prison: recherches sur le système pénitentiaire au XIXe siècle. Paris: Editions du seuil, 1980, p. 9-28

LUBAMBO, C. W. Do Corpo Santo ao Marco Zero: O Bairro do Recife no inicio do século, uma experiência de modernização urbana. Recife: Massangana, 1988 (1991).

MAIA, F. P. Estudo de um Plano de Avenidas para a cidade de São Paulo. São Paulo: Companhia Melhoramentos, 1930.

MAIA, F. P. A remodelação de São Paulo. Revista do Club de Engenharia, Rio de Janeiro, 2F, v. 7, n. 72, p. 3-16, 1941.

MAIA, F. P. Os melhoramentos de São Paulo. São Paulo: Prefeitura Municipal de São Paulo, 1945. 
MARIANNO FILHO, J. A technica do mocambo. Urbanismo e Viação, v. 2, n. 6, p. 169-170, Dezembro de 1939.

MCDOWALL, D. The Light: Brazilian Traction, Light and Power Company Limited. Toronto: University of Toronto Press, 1988.

MEADE, T. 'Civilizing Rio': Reform and Resistance in a Brazilian City (18891930). University Park, PA: Pennsylvania State University Press, 1997.

MENDONÇA, M. T. C. Casas populares: cidades jardins. In: INSTITUTO DE ENGENHARIA DE SÃO PAULO Annaes do $1^{\circ}$ Congresso de Habitação. São Paulo: Escolas Profissionais do Lyceu Coração de Jesus, 1931, p. 139-147, p. 141.

MOTA, A. No tempo do bonde elétrico. Recife: Celpe, 1985, $2^{\mathrm{a}}$ ed.

NEEDELL, J. F. Rio de Janeiro at the Turn of the Century: Modernization and the Parisian Ideal. Journal of Interamerican Studies and World Affairs, v. 25, n. 1, p. 83-103, 1983.

NEEDELL, J. F. A Tropical Belle Époque: Elite Culture and Society in Turn-ofthe-Century Rio de Janeiro. Cambridge: CUP, 1987.

NEEDELL, J. F. Rio de Janeiro and Buenos Aires: Public Spaces and Public Consciousness in Fin-de-Siècle Latin America. Comparative Studies in Society and History, v. 37, n. 3, p. 519-540. Julho de 1995.

NOIRIEL, G. Foucault and History: The Lessons of a Disillusion. Journal of Modern History, v. 66, p. 547-568, 1994.

NOVICK, A. Tecnicos locales y extranjeros en la genesis del urbanismo Argentino, Buenos Aires, 1880-1940. Buenos Aires: manuscrito não publicado, 1990.

NOVICK, A. Tecnicos locales y extranjeros en la genesis del urbanismo porteño, Buenos Aires, 1880-1940. Area, Buenos Aires e Lausanne, n. 1, p. 29-51, Revista de Investigaciones, Facultad de Arquitectura, Diseño y Urbanismo, FADU-UBA- Ecole Polytechnique Fédérale de Lausanne, diciembre de 1992.

NUNES, L. A. P. Prestes Maia na História do Planejamento de Santos. In: MACHADO, D. B. P. (Ed.) Anais do IV Seminário de História da Cidade e do Urbanismo. Rio de Janeiro, 1996, p. 86-97.

OLIVEIRA, F. B. La casa proletária. Urbanismo e Viação, Rio de Janeiro, v. 3, n. 7, p. 187-197, Janeiro de 1940a, p. 187.

OLIVEIRA, F. B. O estado actual da vivenda popular na América. Urbanismo e Viação, Rio de Janeiro, v. 3, n. 7, p. 199-208, Janeiro de 1940b. 
OLIVEIRA, F. B. A casa popular e o aspecto urbanístico das cidades. Urbanismo e Viação, Rio de Janeiro, v. 3, n. 7, p. 209-214, Janeiro de 1940c.

OSELLO, M. A. Planejamento urbano em São Paulo (1889-1961): Introdução ao estudo dos planos e realizações. São Paulo: Dissertação de Mestrado, EAESPFGV, 1983.

OUTTES, J. O Recife pregado à cruz das grandes avenidas: contribuição à história do urbanismo (1927-1945). Recife: Dissertação de Mestrado, MDU-UFPE, 1991.

OUTTES, J. La ville: lieu de la dégénérescence? urbanisme et représentations sociales au Brésil et en Argentine (1920-1945). Paris: Mémoire de DEA, Ecole des Hautes Etudes en Sciences Sociales-Centre de Sociologie Urbaine, CNRS, 1993.

OUTTES, J. O Recife: gênese do urbanismo. Recife: Massangana, 1997, p. 67-70.

OUTTES, J. Disciplining Society through the City? The Birth of Urbanismo (City Planning) in Brazil (1916-1941). Oxford: DPhil Thesis, Oriel College \& School of Geography and Environment, 1999.

PALMER, B. D. Descent into Discourse: The Reification of Language and the Writing of Social History. Philadelphia: Temple University Press, 1990.

DELLA PAOLERA, C. M. In: CONTINENTINO, L. Urbanismo - o plano de Belo Horizonte: impressões de uma viagem recente à Argentina. Arquitetura e Urbanismo, Rio de Janeiro, v. 5, n. 4, p. 222-225, 1940.

PECHMANN, S. Reformas urbanas e classes dominantes no Rio de Janeiro na virada do século: Algumas anotações sobre o debate recente. Águas de São Pedro-MG: Trabalho apresentado no VII Encontro Anual da Associação Nacional de Pós-Graduação e Pesquisa em Ciências Sociais, 16 a 28 de Outubro de 1983.

PECHMANN, S. \& FRITSCH, L. A reforma urbana e o seu avesso: Algumas considerações a propósito da modernização do Distrito Federal na virada do século. Revista Brasileira de História, Rio de Janeiro, v. 5, n. 8-9, p. 139-195, Setembro de 1984-abril de 1985.

PEREIRA, S. G. A reforma urbana de Pereira Passos e a construção da identidade Carioca. Rio de Janeiro: Tese de Doutourado, ECO, UFRJ, 1992 (1996). PONTES, J. A. O. V. Francisco Prestes Maia: o político que não gostava de política. Cidade, São Paulo, v. 3,n. 4, p. 4-9, 1996.

POSTER, M. Foucault and History. Social Research, v. 49, n. 1, p. 116-142, 1982.

PRADO, R. Urbanismo e a criança. Urbanismo e Viação, Rio de Janeiro, v. 4, n. 13, p. 42-43 \& 72, Março de 1941. 
SAN VICENTE, I. M. Planes y proyectos para Rosario 1890-1910. Documentos de Arquitectura Nacional y Americana, n. 21, p. 89-95, 1986.

SARGENT, C. S. The Spatial Evolution of Greater Buenos Aires, Argentina, 1870-1930. Tempe: Arizona State University, 1974.

SCOBIE, J. R. Argentina: A City and a Nation. New York: Oxford University Press, 1971 , p. 260-261.

SCOBIE, J. R. Buenos Aires: From Plaza to Suburb (1870-1910). New York: Oxford University Press, 1974.

SIMÕES, J. G. O setor de obras publicas e as origens do urbanismo na cidade de São Paulo. São Paulo: Dissertação de Mestrado, EAESP-FGV, 1990.

SOUTO, L. R. V. Melhoramentos da Cidade do Rio de Janeiro: Crítica dos trabalhos da respectiva commissão. Rio de Janeiro: Lino Teixeira, 1875.

SOUTO, L. R. V. Melhoramentos da Cidade do Rio de Janeiro: refutação da resposta à crítica dos trabalhos da respectiva segunda commissão. Rio de Janeiro: Lino Teixeira, 1986.

STEPAN, N. 'The Hour of Eugenics': Race, Gender and Nation in Latin America. Ithaca, NY: Cornell University Press, 1991.

SUFFRITI, C. Estudios sobre urbanismo. In: OBRAS SANITÁRIAS DE LA NACIÓN. Primer Congreso Argentino de Urbanismo realizado en Buenos Aires los días 11 al 19 de octubre de 1935: Contribución de Obras Sanitarias de la Nación. Buenos Aires: Imprenta Mercatali, 1935 (1937), pp. 131-138.

TOLEDO, B. L. Prestes Maia e as origens do urbanismo moderno em São Paulo. São Paulo: Empresa das Artes, 1996.

ZAIDAN, N. O Recife nos trilhos dos bondes de burro (1871-1914). Recife: Dissertação de Mestrado, MDU-UFPE, 1991.

ZMITROWICZ, W. O sonho e a realidade do "Plano de Avenidas". Cidade, São Paulo, v. 3 , n. 4 , p. 28-35. 